\title{
7. THE OBLIQUE SEISMIC EXPERIMENT ON DEEP SEA DRILLING PROJECT LEG 65 $^{1}$
}

\author{
R. A. Stephen, Woods Hole Oceanographic Institution, Woods Hole, Massachusetts \\ S. Johnson, Oregon State University, Corvallis, Oregon \\ and \\ B. Lewis, University of Washington, Seattle, Washington
}

\begin{abstract}
The objective of the Oblique Seismic Experiment was to determine the velocity structure of the upper oceanic basement beneath DSDP Site 485 in the mouth of the Gulf of California. To conduct the experiment, we clamped a vertical component borehole seismometer 224 meters below the seafloor in Hole 485A and fired a shooting pattern consisting of eight 12-km-long lines with the Glomar Challenger at its center. From resulting data, we then determined the velocitydepth structure for compressional waves in the upper $2 \mathrm{~km}$ of crust by slope-intercept interpretation of travel times, linear inversion of travel times, and synthetic seismogram modeling, but found no evidence for seismic anisotropy. The hole was not deep enough to determine either attenuation or the interval seismic velocity of the section penetrated by the hole.

We studied lateral inhomogeneity by delay time analysis. It is clear from the data that lateral velocity variations in the shallow crustal structure near the site are not related to topography but to age. There is an apparent thinning or increase in velocity with age of Layer $2 \mathrm{~A}-2 \mathrm{~B}$ which occurs on a scale much smaller (less than 1 m.y.) than do similar phenomena observed by Houtz and Ewing (1976). At present, our observation stands alone and its significance is $\because \mathrm{f}$ ficult to estimate.
\end{abstract}

\section{INTRODUCTION}

The primary objective of the Oblique Seismic Experiment (OSE) conducted on DSDP Leg 65 was to determine the velocity structure of young oceanic crust in the mouth of the Gulf of California and to determine the lateral extent of the structure intersected by the borehole. A secondary objective was to study large scale porosity and crack density in the upper levels of young crust through measurements of seismic velocity, anisotropy, and attenuation. A description of the technique and the results of the first Oblique Seismic Experiment on DSDP Leg 52 can be found elsewhere (Stephen et al., 1979, 1980; Stephen, 1979).

In the Leg 65 experiment, a vertical component geophone was clamped at $3215 \mathrm{~m}$ BRF (below rig floor) in Hole 485A (Table 1), while the Kana Keoki executed the shooting pattern shown in Figure 1. The set of vertical component seismograms obtained is presented in the figures of the appendix.

The topography under the shooting pattern consists of three valleys and three ridges with a strike of $\mathrm{N} 30^{\circ} \mathrm{E}$ (Fig. 2). The ridges are sediment-free (less than 25 meters thick) and there is less than 150 meters of sediment in the valleys. The bathymetry and topography of the Tamayo Fracture Zone region, including the area of the site, and the results of regional seismic refraction experiments using sonobuoys and ocean bottom seismometers, have been discussed by Lewis (1979) and McClain and Lewis (1980).

In this chapter we will discuss the seismic velocity structure for both compressional and shear waves within $12 \mathrm{~km}$ of Site 485 to a depth of $2 \mathrm{~km}$. The previous seis-

\footnotetext{
${ }^{1}$ Lewis, B. T. R., Robinson, P. et al., Init, Repts. DSDP, 65: Washington (U.S. Govt. Printing Office).
}

Table 1. Significant depths in Hole 485A.

\begin{tabular}{lccc}
\hline & $\begin{array}{c}\text { Depth from } \\
\text { Rig Floor } \\
(\mathrm{m})\end{array}$ & $\begin{array}{c}\text { Depth from } \\
\text { Mud Line } \\
(\mathrm{m})\end{array}$ & $\begin{array}{c}\text { Depth into } \\
\text { Basement } \\
(\mathrm{m})\end{array}$ \\
\hline Sea Level & 10 & & \\
Mud Line & 2991 & & \\
Basement & 3144 & 153 & 71 \\
Geophone Position & 3215 & 224 & 71 \\
Bottom of Hole & 3322 & 331 & 178 \\
\hline
\end{tabular}

mic work using receivers placed on or above the seafloor did not resolve structure on this scale. Though velocity structure varied significantly under both ridges and valleys, there was no evidence for seismic anisotropy. The hole was not deep enough (Table 1) to determine attenuation or to determine the interval velocity of the section penetrated by the hole.

\section{DATA INTERPRETATION}

The velocity-depth structure for compressional waves was determined from travel times by the slope-intercept method, and by linear inversion (Dorman and Jacobson, 1980), and from vertical component amplitudes by synthetic seismogram modeling (Stephen, 1977). Lateral inhomogeneity was studied using delay time analysis. Two phase velocities were apparent: one between 4.3 and $5.1 \mathrm{~km} / \mathrm{s}$, corresponding to Layer $2 \mathrm{~B}$ (Houtz and Ewing, 1976), and one between 5.2 and $6.0 \mathrm{~km} / \mathrm{s}$, corresponding to Layer $2 \mathrm{C}$. No arrivals were detectable with a velocity of approximately $3.6 \mathrm{~km} / \mathrm{s}$, which is the estimated velocity of the interbedded sediment/basalt sequences intersected by the borehole.

Before analyzing the travel times, they were first corrected for basement topography by subtracting the water delay time based on estimated refractor velocities 


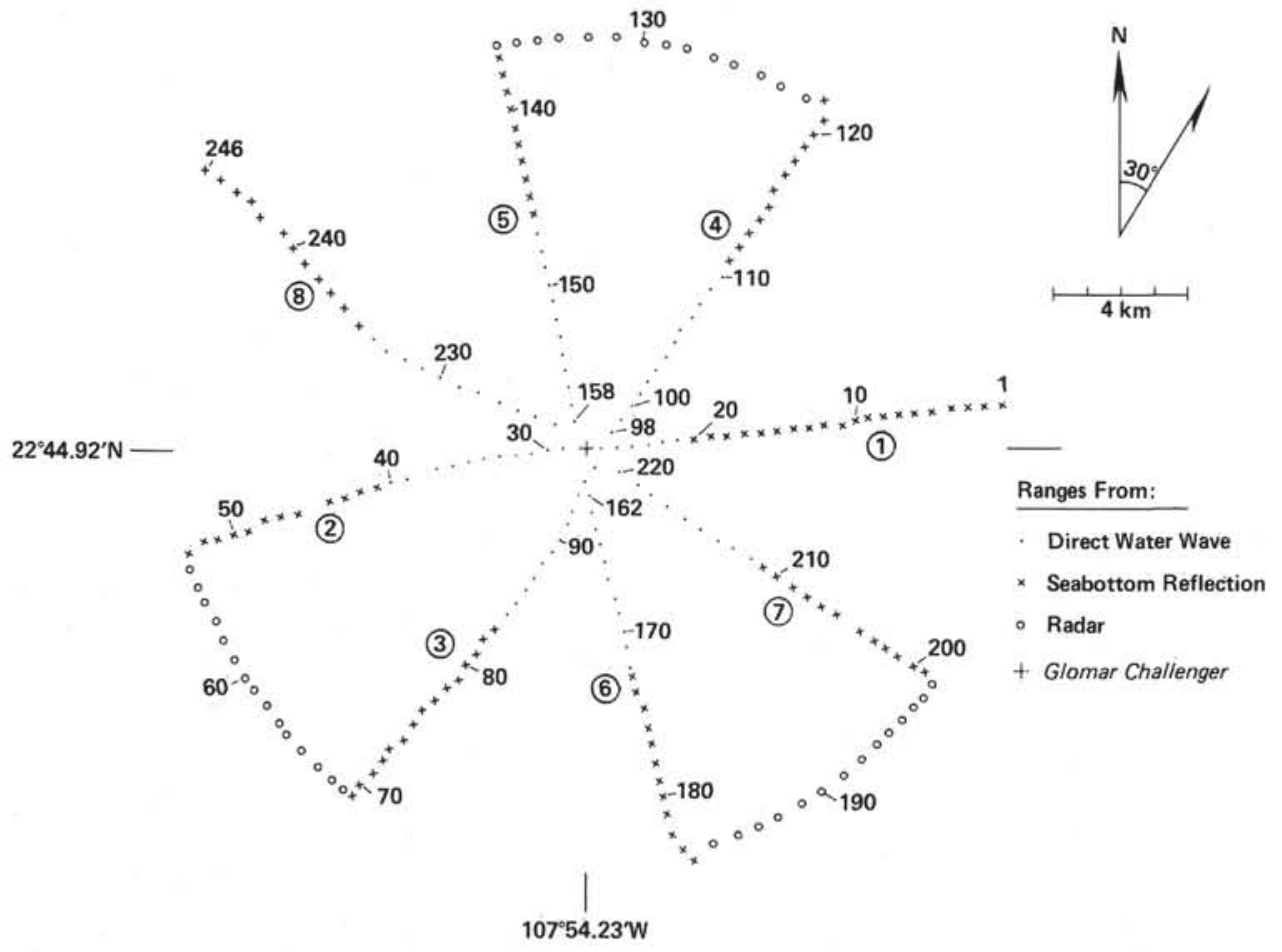

Figure 1. Shot locations (relative to the Glomar Challenger) for the Oblique Seismic Experiment. The estimated strike of the ridge axis is $\mathrm{W} 30^{\circ} \mathrm{E}$. Line numbers referred to in the text are indicated by the circled numbers.

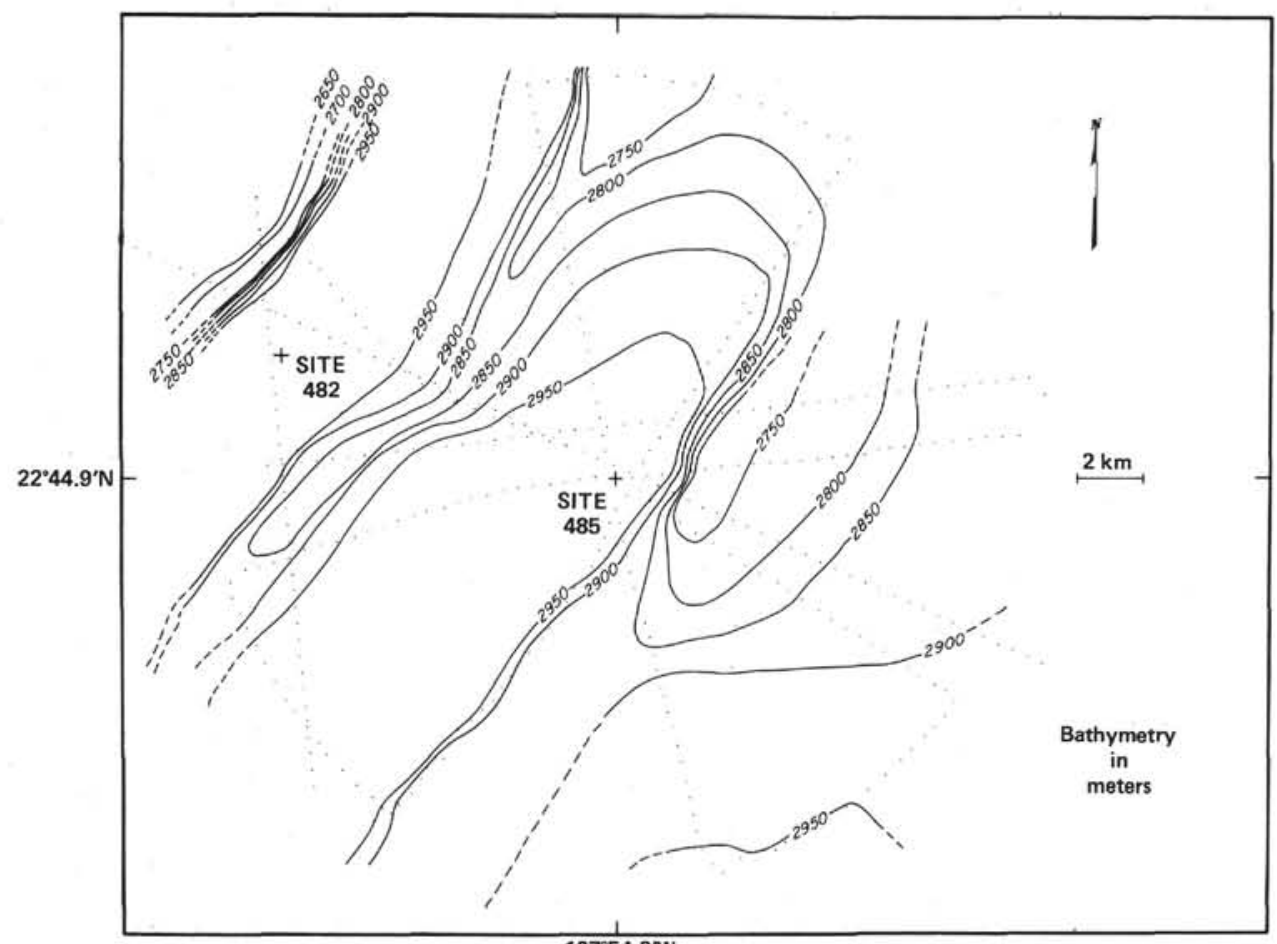

Figure 2. Bathymetry, contoured at $50-\mathrm{m}$ intervals for the region within $12 \mathrm{~km}$ of Site 485 . The ridges above approximately $2950 \mathrm{~m}$ are free of sediment. 
of $5.0 \mathrm{~km} / \mathrm{s}$ for Layer $2 \mathrm{~B}$ and $5.7 \mathrm{~km} / \mathrm{s}$ for Layer $2 \mathrm{C}$. The sediment velocity was assumed to be indistinguishable from that of water. The maximum error in this assumption, based on a maximum sediment thickness of 150 meters and the maximum measured sediment velocity of $1.61 \mathrm{~km} / \mathrm{s}$, is $0.007 \mathrm{~s}$, which is insignificant. Figure 3 provides summaries of the Layer $2 \mathrm{~B}$ and $2 \mathrm{C}$ velocities determined by the slope-intercept method for each line. Note that there is no indication of azimuthally dependent velocity in either case. In addition, although the velocities differ by as much as $0.7 \mathrm{~km} / \mathrm{s}$, the variations have no obvious pattern.
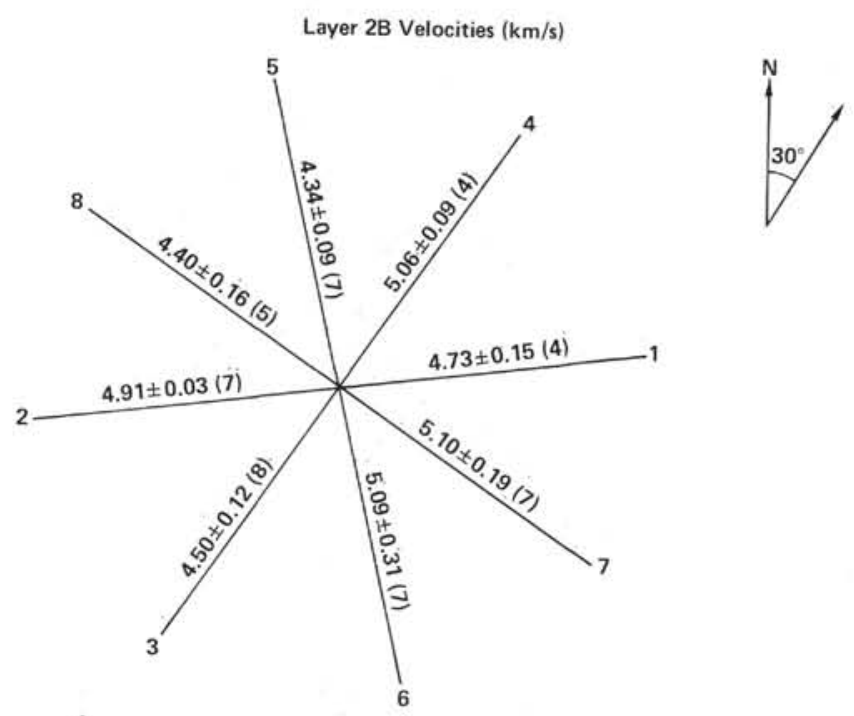

A

Average Velocity: $4.79 \pm 0.12$
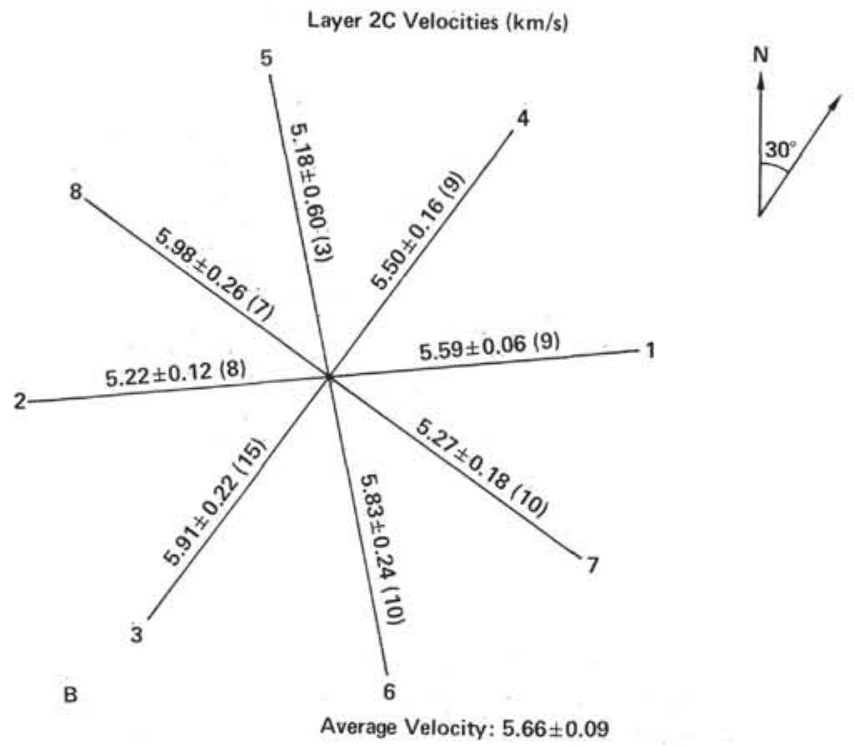

Figure 3. Summary of the Layer 2B (Fig. 3A) and 2C (Fig. 3B) Compressional wave velocities determined for each line. There is no evidence for azimuthally dependent velocity. The number of points used in each determination is shown in parentheses.

\section{Homogeneous Layer Models: Travel Times}

Although there appears to be rather marked lateral heterogeneity, we will discuss an average velocity-depth structure for the area, assuming lateral homogeneity. The appropriateness of this assumption is questionable, but it is the traditional assumption in studying ocean crust. Figure 4 summarizes the results. The slope-intercept solution gives a thickness of $0.235 \pm 0.065 \mathrm{~km}$ for Layer $2 \mathrm{~A}$, the low velocity layer $(3.6 \mathrm{~km} / \mathrm{s})$ penetrated by drilling. Layer $2 \mathrm{~B}$ is about $0.893 \pm 0.181 \mathrm{~km}$ thick and has a velocity of $4.8 \mathrm{~km} / \mathrm{s}$. The layer $2 \mathrm{C}$ velocity is $5.7 \mathrm{~km} / \mathrm{s}$, and no Layer 3 velocities were observed. The trend in this solution is followed by the linear inversion model (Dorman and Jacobson, 1981) except that continuous gradients replace steps.

Shear wave energy was evident on Lines $2,4,6$, and 7. The presence of shear waves on some lines and not others can be explained by the sensitivity of the compressional to shear wave transmission coefficient at the sediment/basement interface to the compressional wave velocity of Layer 2A (White and Stephen, 1980; Spudich and Orcutt, 1980). When the $P$-wave velocity of Layer $2 \mathrm{~A}$ exceeds the phase velocity of the shear wave arrivals, the conversion to shear waves is relatively efficient; otherwise, conversion is poor. Of course, the scattering of shear waves by topography and lateral inhomogeneities would also make $S$-wave arrivals less coherent. The best velocity estimate for the shear wave energy in this experiment is $3.11 \pm 0.28 \mathrm{~km} / \mathrm{s}$, which corresponds to arrivals from Layer 2C (Poisson's ratio of 0.284 ). The standard error in the intercept time is too large to give meaningful information on shear wave velocity for Layers $2 \mathrm{~A}$ and $2 \mathrm{~B}$.

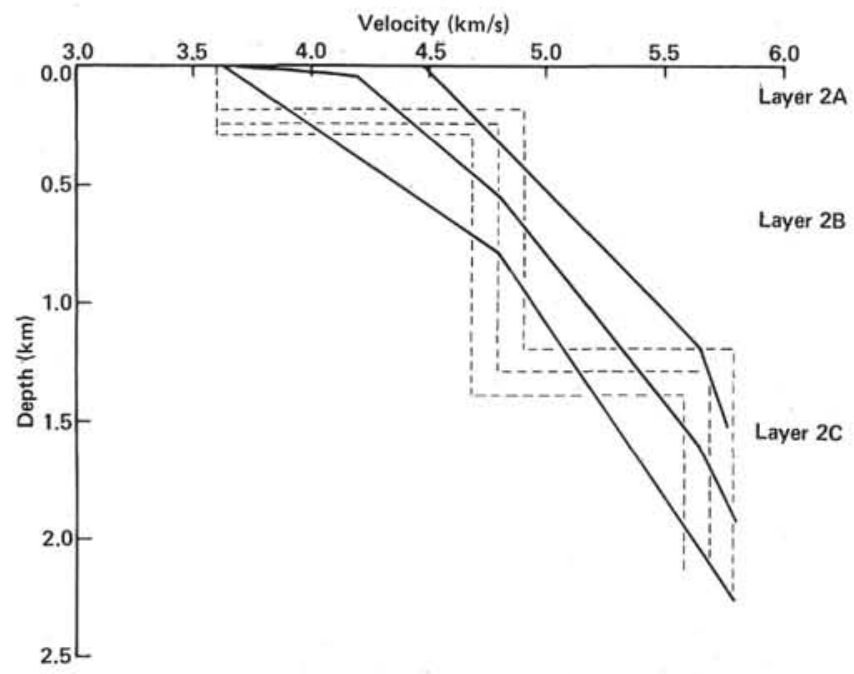

Figure 4. Compressional wave velocity-depth structure based on slope-intercept method (dashed lines) and the linear inversion method of Dorman and Jacobson (1981) (solid lines). Bounds represent standard errors and $95 \%$ confidence limits, respectively. The inversion solutions and bounds presume averaging into layers indicated by the straight line segments. 


\section{Homogeneous Layer Models: Amplitudes}

To refine further the average velocity-depth structure, we conducted amplitude analysis. The velocitydepth models used to simulate this behavior are shown in Figure 5, and the corresponding synthetic seismograms are shown in Figure 6. We selected Line 4 as being "typical" of the area since it was a complete line with no bad shots and the basement topography underneath the line was relatively smooth. The key features of the compressional wave energy on this line are as follows: (1) large amplitudes between 4 and $5.5 \mathrm{~km}$; (2) small amplitudes between 5.5 and $7 \mathrm{~km}$; (3) large amplitudes between 7 and $9.5 \mathrm{~km}$; (4) small amplitudes between 9.5 and $11 \mathrm{~km}$; (5) large amplitudes between 11 and $12 \mathrm{~km}$; and (6) small amplitudes again between 12 and $13 \mathrm{~km}$.

Model I is based on the mean solution of the Dorman-Jacobson travel-time inversion method extended downward to include Layer 3-type structures. This model gives large amplitude arrivals throughout the ranges of interest and is clearly inadequate. In order to produce the low amplitudes between 5.5 and $7.0 \mathrm{~km}$, it was necessary to introduce a homogeneous layer between 0.5 and $1.1 \mathrm{~km}$ depth (Models IIA, IIB, and IIC in Figs. 5 and 6). The upper gradient focuses energy into

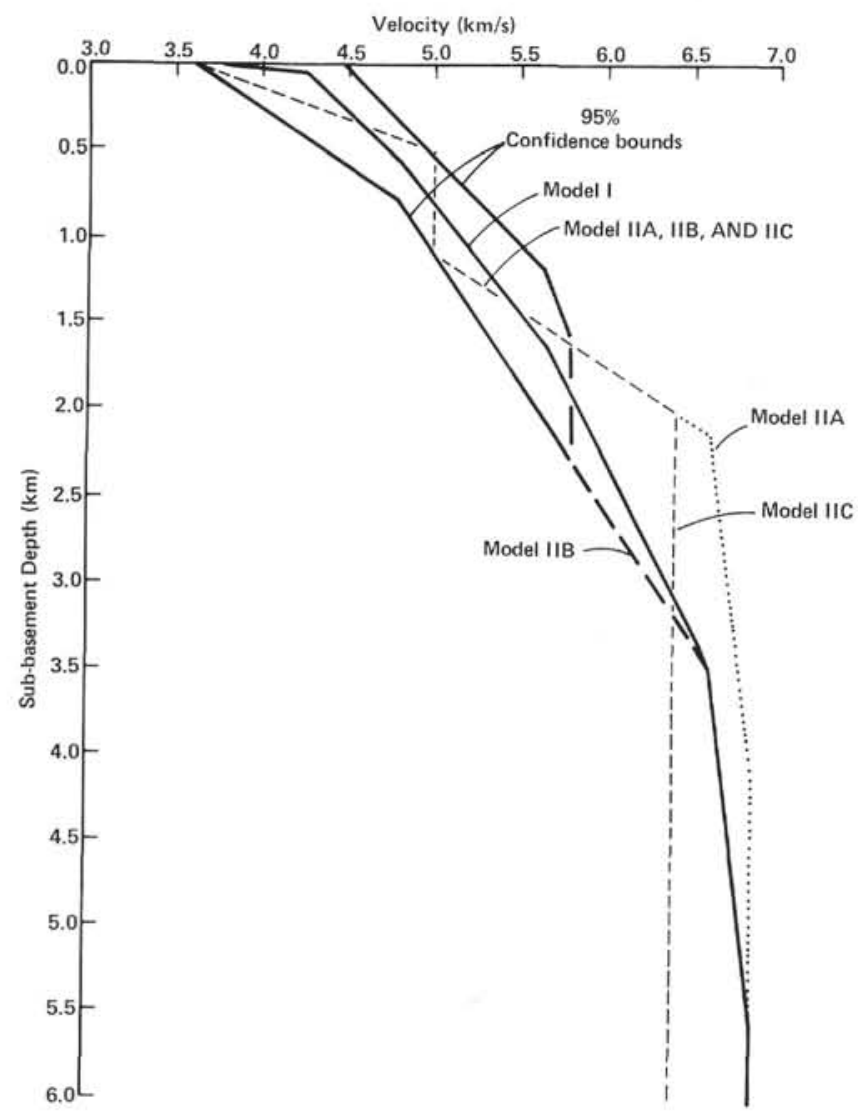

Figure 5. Velocity-depth models (roman numerals) associated with the synthetic seismograms shown in Figure 6 . The $95 \%$ confidence bounds of the linear inversion method of Dorman and Jacobson (1980) are also shown. In computing the synthetic seismograms, the gradients were approximated by homogeneous layers with a thickness less than half of the shear wavelength.

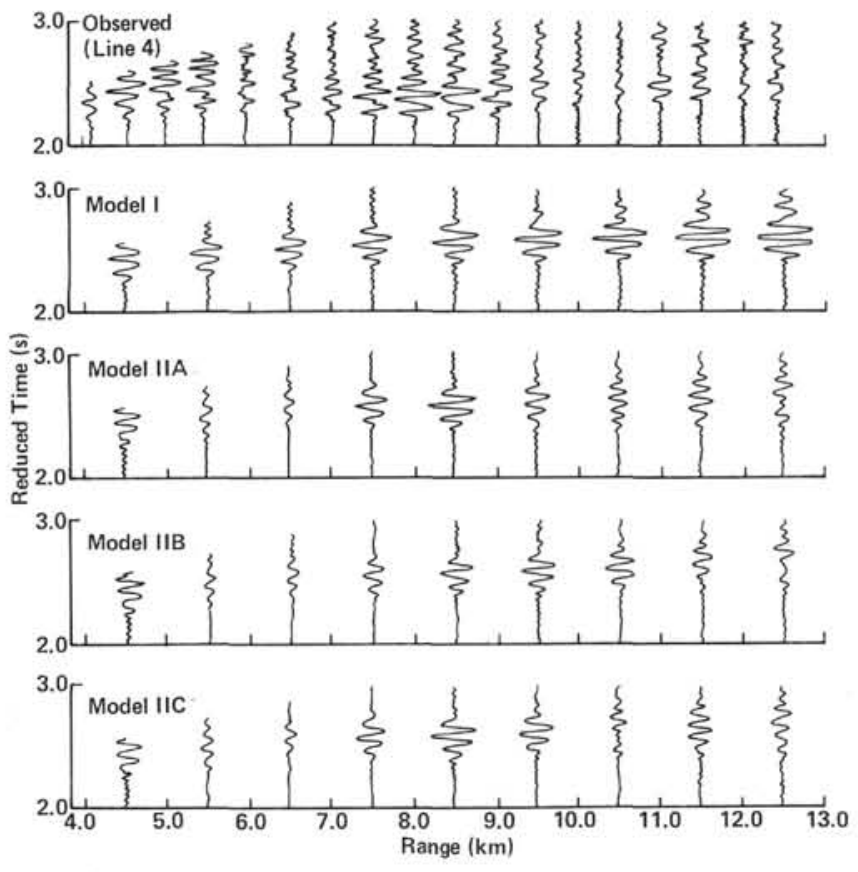

Figure 6. Synthetic seismograms associated with the velocity-depth models shown in Figure 5 compared to the observed data of Line 4 (Figure 1). Times are reduced at $6.0 \mathrm{~km} / \mathrm{s}$ and the amplitudes for ranges greater than $7.0 \mathrm{~km}$ are weighted by $(\text { range/7.0 })^{2.9}$. The synthetic seismograms were calculated by the reflectivity method as modified for borehole receivers by Stephen (1977).

the 4.0 and $5.5 \mathrm{~km}$ region, the homogeneous layer causes a shadow zone between 5.5 and $7.0 \mathrm{~km}$, and the lower gradient focuses energy into the 7.0 to $9.5 \mathrm{~km}$ region.

The amplitude behavior at ranges greater than $9.5 \mathrm{~km}$ is controlled by structure deeper than the limits of the travel-time solution. The three models (IIA, IIB, and IIC) have identical velocity-depth structures up to velocities of $5.5 \mathrm{~km} / \mathrm{s}$. Model IIA has one continuous gradient from the homogeneous layer down to a typical Layer 3 structure. This gives amplitude minima at 10.5 and $12.5 \mathrm{~km}$, but the amplitudes are not as low as in the real data. Model IIB represents an attempt to produce the 9.5 to $11.0 \mathrm{~km}$ low amplitude region as a shadow zone caused by a second homogeneous layer at a depth of between 1.6 and $2.5 \mathrm{~km}$. This failed. The effect of ignoring Layer 3 structure is shown in Model IIC-the best fit to the observed data. It is identical to Model IIA except for the absence of Layer 3. Travel time curves for the three models are shown in Figure 7. It is unwise to model amplitude behavior without travel-time constraints, and the velocity-depth structures beyond 5.5 $\mathrm{km} / \mathrm{s}$ in Models IIA, IIB, and IIC should not be considered definitive.

\section{Delay-Time Analysis}

It is not unreasonable to suspect that the velocity structure under the ridges may differ from that under the valleys. This was checked by calculating the velocities obtained using shots over topography of less than 150 meters (valleys) and shots over topography greater than 150 meters (ridges). Topography in this context is the height of the basement surface above a datum level, 


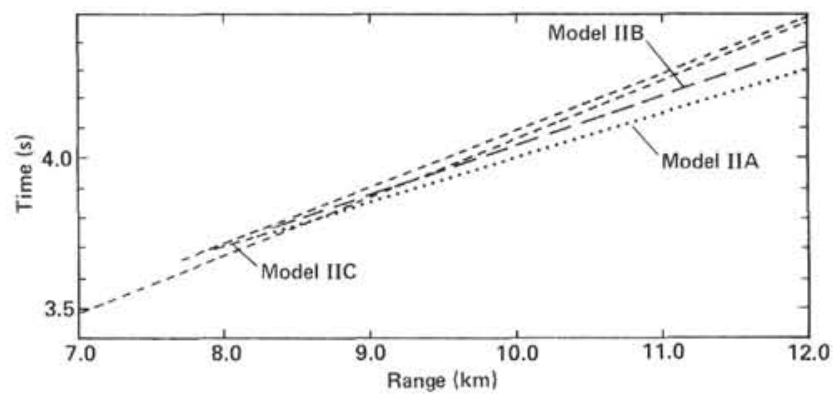

Figure 7. Travel-time curve for Models IIA, IIB, and IIC of Figures 5 and 6. Structure deeper than the inverse solution affects both travel-time and amplitudes within the observed ranges. Thus, although all models are consistent with the inverse solution only Model IIC satisfies the observed travel-time and amplitudes.

defined as the basement depth at Site 485 (3134 meters below sea level), and varies from 0 to 472 meters. Offsets in range were made to allow for the effect of nonvertical ray paths in the water column. Valleys are generally sediment-filled, and ridges are generally sediment-free (see Appendix).

For Layer $2 \mathrm{~B}$, the velocity under the valleys is $4.64 \pm 0.16 \mathrm{~km} / \mathrm{s}$ and under the ridges, $5.12 \pm 0.16$ $\mathrm{km} / \mathrm{s}$. Since these were not considered to be the same refractor, delay time analysis for Layer $2 \mathrm{~B}$ arrivals was not carried further. For Layer $2 \mathrm{C}$, the velocity under the valleys is $5.62 \pm 0.10 \mathrm{~km} / \mathrm{s}$ and under the ridges is $5.61 \pm 0.16 \mathrm{~km} / \mathrm{s}$. Since these do not differ significantly from each other or from the average Layer $2 \mathrm{C}$ velocity of $5.66 \pm 0.09 \mathrm{~km} / \mathrm{s}$, it is assumed that the Layer $2 \mathrm{C}$ refractor is the same throughout the area.

The average combined Layer 2A-2B delay times for two of the ridges and two valleys in the area are shown in Figure 8. The estimated standard measurement error in the delay times is $\pm 0.033 \mathrm{~s}$, including the uncertainty in basement topography. The scatter in the delay times, therefore, falls mostly within the measurement error.

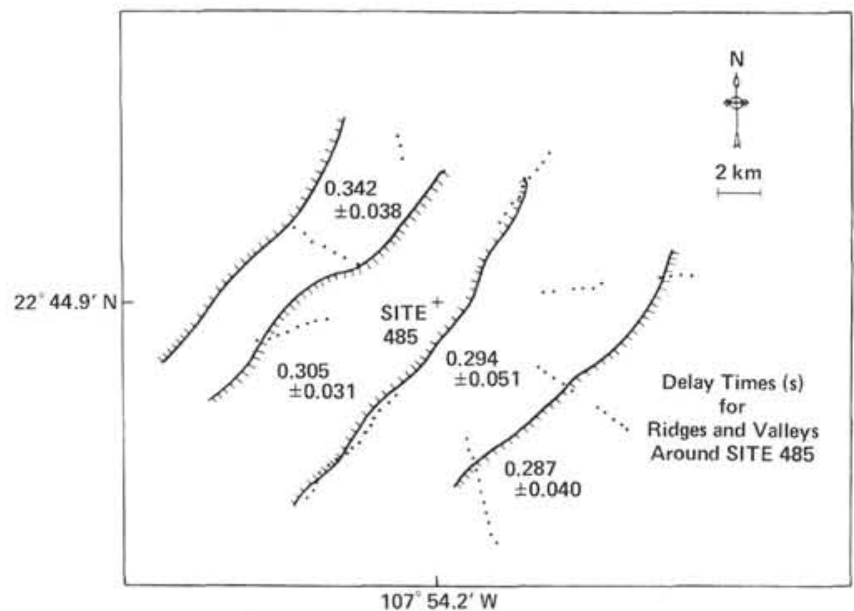

Figure 8. Average Layer 2A-2B delay times (in seconds) for the ridges and valleys around Site 485 . The valleys and ridges are defined by the 2980-m contour of basement topography. Dots represent the location of shots used in the compilation.
Since mean delay times differ as much between the two ridges as between the ridges and valleys, we cannot infer the presence of different underlying structures.

The Layer 2A-2B delay times decrease systematically with age. If one assumes a constant depth to the Layer $2 \mathrm{C}$ refractor, the combined Layer $2 \mathrm{~A}-2 \mathrm{~B}$ velocity increases from $4.1 \mathrm{~km} / \mathrm{s}$ under the western hill to $4.7 \mathrm{~km} / \mathrm{s}$ under the eastern valley. If one assumes a constant velocity for Layer $2 \mathrm{~A}-2 \mathrm{~B}$, the depth to the Layer $2 \mathrm{C}$ refractor decreases from $1.40 \mathrm{~km}$ under the western hill to $0.99 \mathrm{~km}$ under the eastern valley.

\section{CONCLUSIONS}

Amplitude analysis of the average velocity-depth structure for the upper $2 \mathrm{~km}$ of the ocean crust near Site 485 indicates that a combination of a constant velocity layer with layers of constant velocity gradient gives the best fit to the data (Fig. 6). It is conceivable, however, that lateral velocity variations may affect the observed amplitudes.

It is clear from the data that there are lateral velocity variations in the upper levels of the crust which vary with age rather than topography. The apparent thinning or increase in velocity with age of Layer $2 \mathrm{~A}-2 \mathrm{~B}$ appears to occur much more quickly at this site (in less than 1 m.y.) than it does on the Mid-Atlantic Ridge, where it occurs over a period of 25 m.y. (Houtz and Ewing, 1976). At present, our observation stands alone, and its significance is difficult to estimate.

\section{ACKNOWLEDGMENTS}

We would like to thank Drs. L. M. Dorman and R. S. Jacobson for their computer program to perform linear inversion of travel-time data. M. D. Allison played a key role in reducing the data. Our appreciation is also extended to P. Barrows and P. Foster who typed the manuscript. Drs. R. P. Von Herzen and G. M. Purdy reviewed the paper.

\section{REFERENCES}

Dorman, L. M., and Jacobson, R. S., 1981. Linear inversion of body wave data. Part 1: Velocity structure from travel times and ranges. Geophyics, 46:138-151.

Houtz, R., and Ewing, J., 1976. Upper crustal structure as a function of plate age. J. Geophys. Res., 81:2490-2498.

Lewis, B. T. R., 1979. Periodicities of volcanism and longitudinal magma flow on the East Pacific Rise at $23^{\circ} \mathrm{N}$. Geophys. Res. Lett., 6:753-756.

McClain, J. S., and Lewis, B. T. R., 1980. A seismic experiment at the axis of the East Pacific Rise. Mar. Geol., 35:147-169.

Spudich, P., and Orcutt, J., 1980. Petrology and porosity of an oceanic crustal site: results from wave form modelling of seismic refraction data. J. Geophys. Res., 85:1409-1433.

Stephen, R. A., 1977. Synthetic seismograms for the case of the receiver within the reflectivity zone. Geophys. J. R. Astron. Soc., $51: 169-181$.

1979. The Oblique Seismic Experiment in oceanic crustequipment and technique. Mar. Geophys. Res., 4:213-226.

Stephen, R. A., Louden, K. E., and Matthews, D. H., 1979. The Oblique Seismic Experiment on DSDP Leg 52. In Donnelly, T., Francheteau, J., Bryan, W., Robinson, P., Flower, M., Salisbury, M., et al., Init. Repts. DSDP, 51, 52, 53, Pt. 1: Washington (U.S. Govt. Printing Office), 675-704.

White, R. S., and Stephen, R. A., 1980. Compressional to shear wave conversion in oceanic crust. Geophys. J. R. Astron. Soc., 63: $547-565$. 


\section{APPENDIX}

Vertical component seismograms obtained with the geophone clamped $71 \mathrm{~m}$ into basement at Hole $485 \mathrm{~A}$. Times are reduced at 6.0 $\mathrm{km} / \mathrm{s}$ and the amplitudes for ranges greater than $7.0 \mathrm{~km}$ are weighted by (range/7.0) 2.9 . (These values are empirically chosen to produce a plot with satisfactory appearance.) The data have been bandpassfiltered between 5 and $30 \mathrm{~Hz}$. Line numbers are defined in Figure 1 , Below each seismogram, the bathymetry obtained during the experiment (solid lines) and the basement topography (dashed lines) inferred from the reflection profiling data obtained during the site survey (Lewis, 1979) have been plotted.
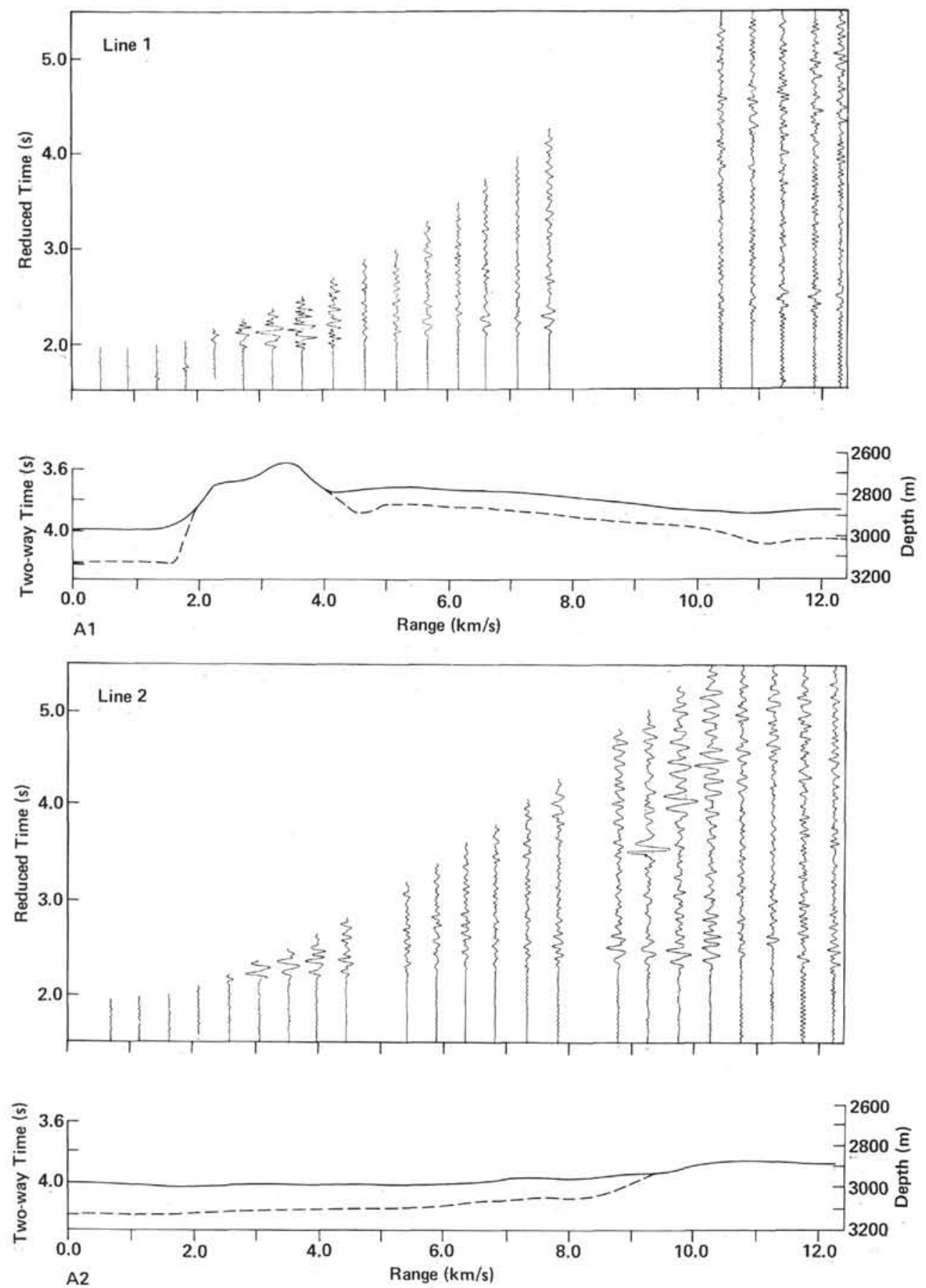

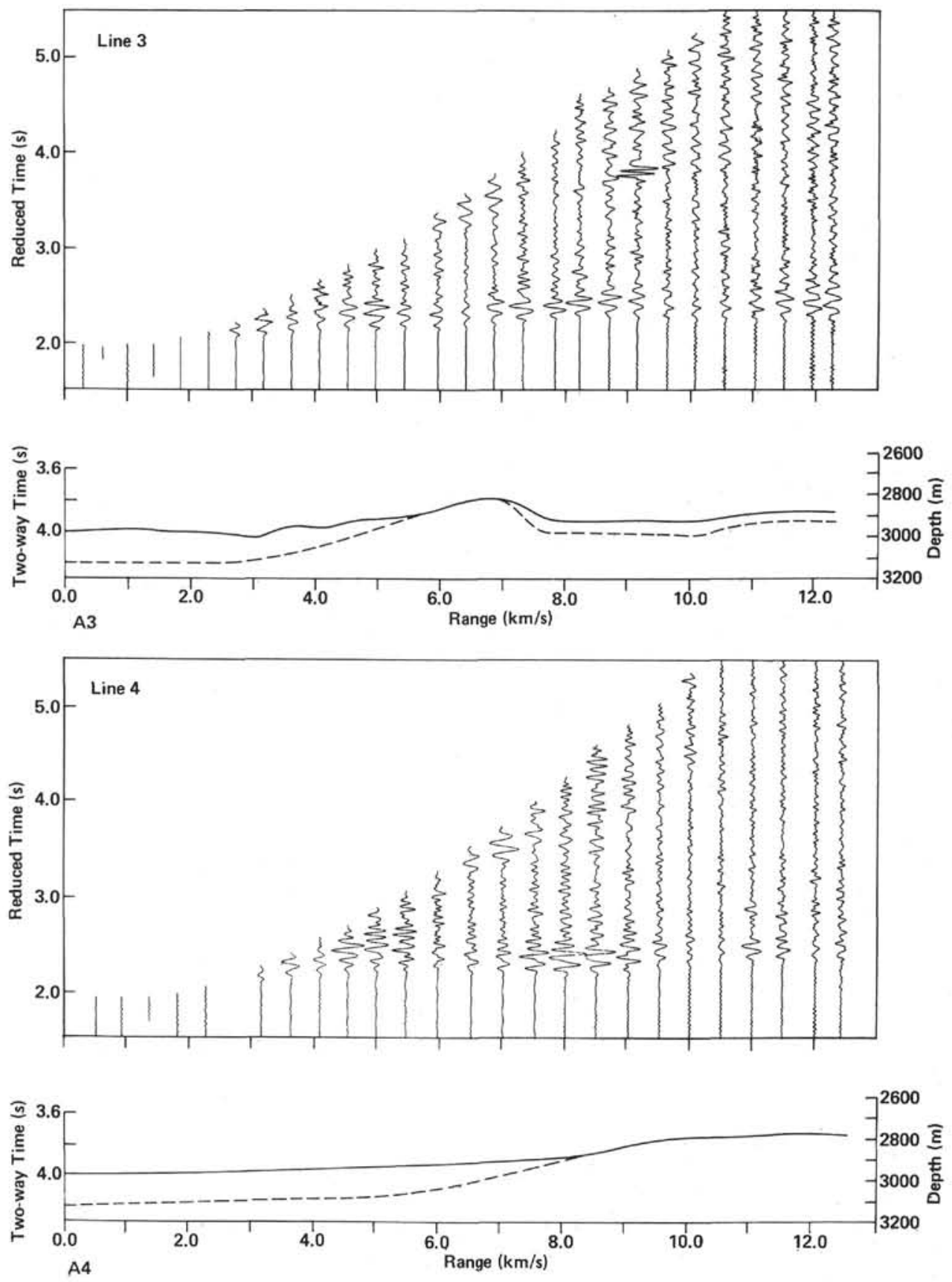

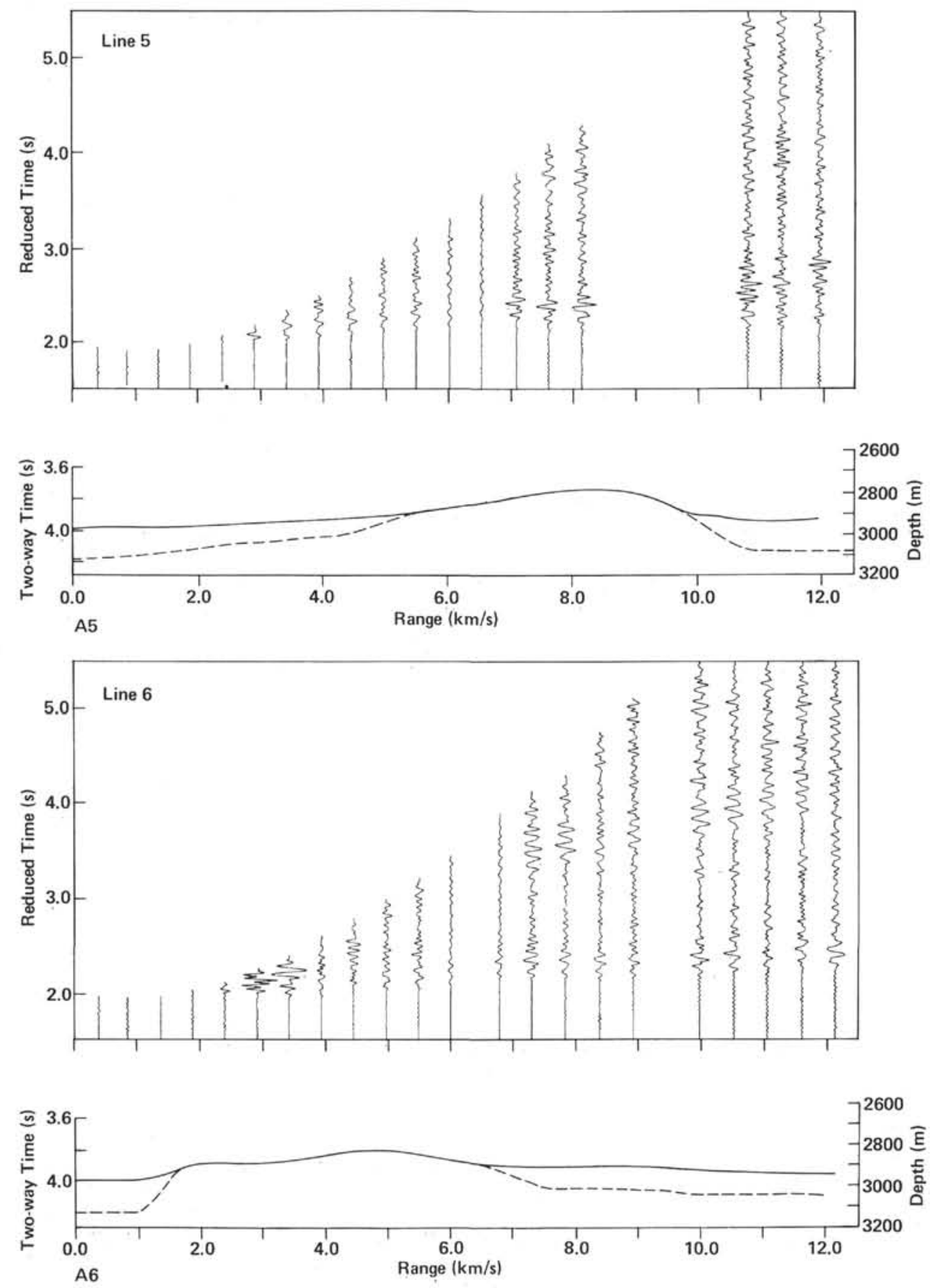

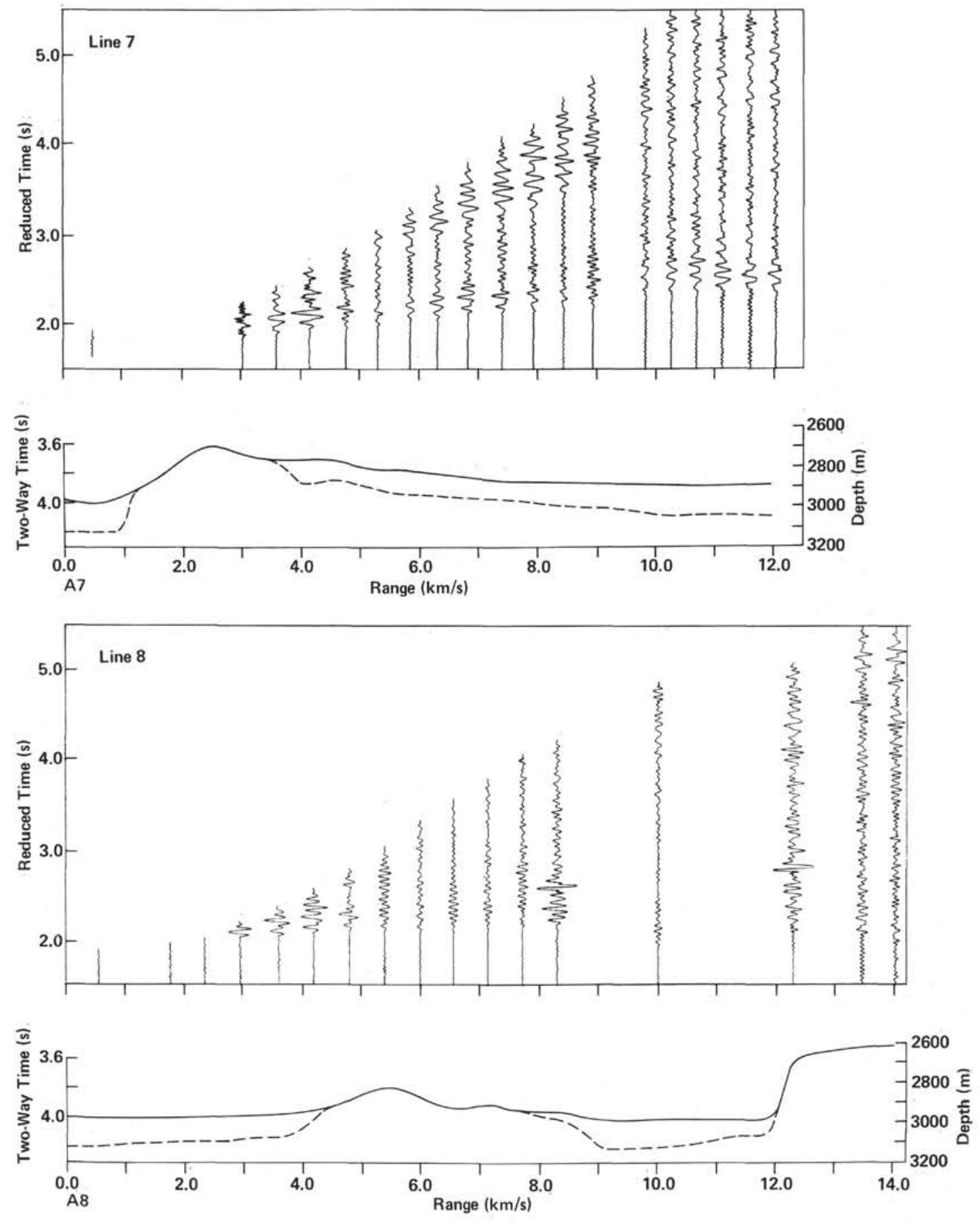